\title{
Effect of the Friction Coefficient on Clinch Joints
}

\author{
SZ. JóNÁS' ${ }^{1}$ M. TISZA² \\ University of Miskolc, Institute of Materials Sciences and Technology, Department of Mechanical Technology \\ szabolcs.jonas@gmail.com¹, miklos.tisza@uni-miskolc.hu²
}

Abstract. In this study the effect of the friction coefficient on the clinch joints was examined in experimental and numerical way also. The knowledge of the frictional behaviour during the mechanical joining (i.e. clinching) is important from the point of view of resultant geometry which is related to and influence the strength of the joints, and furthermore the maximal forming force is limited by the tool's failure load which can be reach with a nonfavourable frictional condition, as well the aesthetic aspect are also has an importance in some special cases (e.g. in automotive industry).

\section{Introduction}

The clinch joints are mechanical joining by local plastic forming technique between similar or dissimilar usually thin sheets with variable thicknesses. The cross section of a clinched joint can be seen in Figure 1. The joining technique is widely used by the automotive industry as a fast, costeffective and eco-friendly method in place of spot welded or self-piercing riveted joints [1]. Due to the increasing interest of the joining technique the research of the joints is also getting increased. In this study one of the most important influencer parameter of a forming process namely the frictional behaviour is analysed by experiments and through FE simulations.

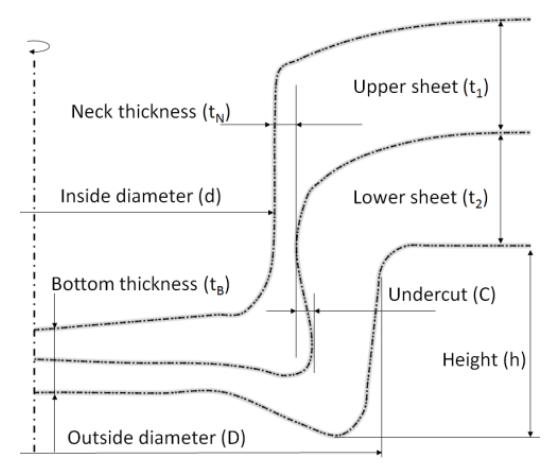

Figure 1. Cross section and main geometrical parameters of a round clinch joints.

The frictional behaviour during metal forming processes is widely researched because of its importance. The high frictional coefficient between the blanks (sheets) and the tools leads to higher forming forces and a well-lubricated condition provides less, at the same time the usage of lubricants is highly pollutes the environment [2],[3]. This impact on the environment is not beneficial, so the question is how to find an optimal case without extra costs. FE simulations can provide optimal 
solutions in severe cases, by the way the forming simulations are often use the Coulomb friction law which does not show a proper result during the process because the value of the friction coefficient in real-life cases is continuously changing, after all the results can be useful for the designers of the technology[4],[5]. For more information, the experimental set ups can validate the theoretical values and the results can be implemented into the industrial daily practice. The clinch joints were investigated in some papers [6],[7] in the literature in the point of view of friction and found that the frictional coefficient has an important impact on the final results of the joints.

\section{Experimental and numerical investigation of the joints}

The frictional behaviour of the joints was analysed via FE simulations and experimentally. Forming forces and geometrical parameters of the joints were compared. The material type of the tests and the simulation is DP600 steel.

\subsection{FE Simulations}

The FE model of the joints were built in ANSYS WB 19.2 and in previous studies the model is presented and validated such as in [8]. The FE model assumed the joining process as a 2D axisymmetrical problem (Figure 2). The material model was fitted to tensile test results and extrapolated by the Swift law. The FE model consider the material as nonlinear and isotropic hardening. The model uses second order elements. Due to the occurring of high plastic strains during the simulation it is a good way of simplifying the process, and according to the measured forming force-punching tool displacement curves, and the comparison of the cross sections of the joints compared to the simulated ones, it is a good approximation of the real-life conditions.

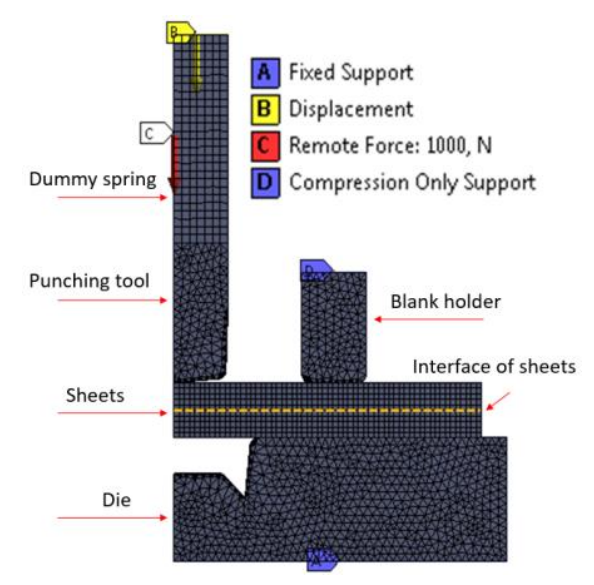

Figure 2. FE model of the joining system.

The effect of the friction can be taken into consideration with the friction coefficient between the contacts of the parts which was assumed in the first iteration of 0.1 for every of the contacting regions. Three simulation just analysed the impact of the friction coefficient of the lubrication condition of the interface of the sheets, and in two simulations the friction coefficient uniformly changed. In the Table 1 
the applied values can be seen. The friction coefficient of $\mu=0.03$ assumes a well-lubricated case, and when the $\mu=0.2$ is used to the contacts a rough surface is assumed.

\begin{tabular}{|c|c|c|}
\hline & Sheet-Sheet interface & $\begin{array}{c}\text { All other contact } \\
\text { regions }\end{array}$ \\
\hline$\mu=0.03$ & 0.03 & 0.1 \\
\hline$\mu=0.1$ & 0.1 & 0.1 \\
\hline$\mu=0.2$ & 0.2 & 0.1 \\
\hline$\mu=0.03 \_$all & 0.03 & 0.03 \\
\hline$\mu=0.2 \_$all & 0.2 & 0.2 \\
\hline
\end{tabular}

Table 1. Assumed friction coefficients on the contacts.

The results of the simulation are the forming force - relative punch displacement (F-d) curves (Figure 3 ) and the formed shapes of the joints. From the position data of the FE nodes the sheets after forming can be draw curves which can represent the undercut (Figure 4).

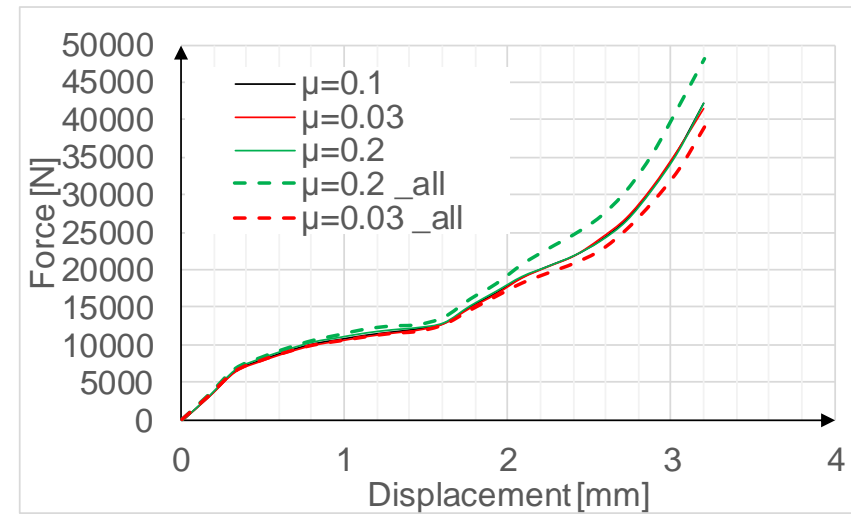

Figure 3. F-d curves with different frictional coefficients.

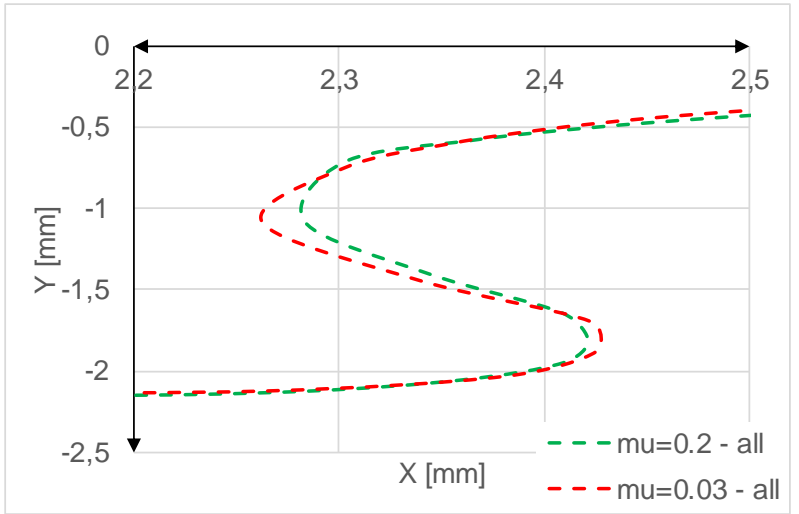

Figure 4. Comparison of the undercuts.

As it can be seen the F-d curves of the variable interface friction coefficient the frictional behaviour has negligible effect, in opposite the uniformly small or high coefficient of friction has a high impact on the forming force need, which can be dangerous in the point of view of expected tool life. The highest deviation raised after the lower sheet reached the die and the material starts to flow inside the groove. The comparison of the undercuts of the joints leads to an interesting result. The higher friction coefficient provides a smaller undercut, which is not favourable in the point of view of joint strength according to Coppiteres work [7]. Based on the FE results we can state that the lower friction coefficient leads to a better joint.

\subsection{Experiments}

The prove that the lower friction coefficient is better of the point of view of joint producing and strength an experimental work was done. A TOX clinching tool was used to producing joints. The tool was set up in an MTS electro-hydraulic testing machine. The forces and displacements were registered during the joining. For the "well-lubricated" case specimen was prepared with PTFE spray on its surfaces. The idea is that the PTFE provides a well-known low frictional condition. For the high frictional behaviour the roughness of the joined sheets was changed by a 120 grid abrasive paper. 


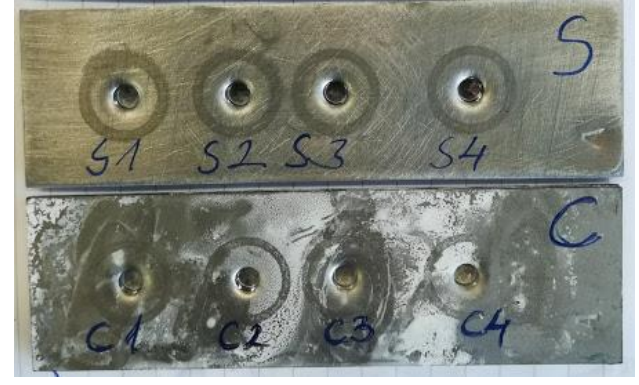

Figure 5. Prepared specimens with the joints.

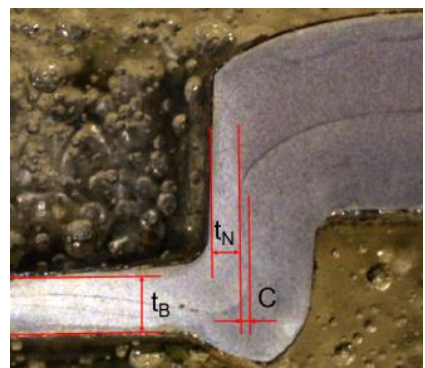

Figure 6. Measured parameters.

Both pair of sheets (specimens) were joined together in four points next to each other (Figure 5). The specimen signed by " $\mathrm{S}$ " is the rough surfaced specimen and the specimen signed by " $\mathrm{C}$ " is the one which sprayed with PTFE. Every joint analysed by microscopy and measured the three parameters, bottom thickness $\left(t_{B}\right)$, neck thickness $\left(t_{N}\right)$ and undercut $(C)$ according to the Figure 6 .

The results of the measured and averaged values were depicted in the following diagram (Figure 7.).

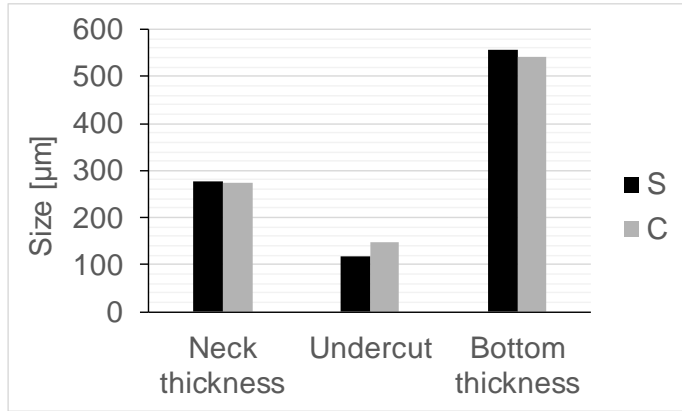

Figure 7. Comparison of measured parameters.

The results show that undercut has the highest impact. The bottom thickness results show a deviation also, but it can be negligible due to its basically higher values compare to the other two values. A small increasing can be measured in the neck thickness in case of rough surface. The increasing value of neck thickness is favourable because the tensile strength of the joints highly depends on it [7], [9]. The forming forces according to the measured values are slightly affected $(\sim 1500 \mathrm{~N})$ by the friction during the experiments.

\section{Summary}

The FE simulations and the experimental also show that the friction coefficient has an impact on the geometry on the joints. The well-lubricated joining setup leads to better joints in the point of view of cross-tension type of loading with the lower forming force need which is favorable in serial production, but at the same time the higher frictional coefficient leads to a $\sim 7 \%$ higher resistance against simple tension loading condition because of the small increase in the neck thickness 


\section{Acknowledgement}

Supported by the ÚNKP-19-3 New National Excellence Program of the Ministry for Innovation and Technology.

\section{References}

[1] Sz. Jónás, M. Tisza (2018), Numerical investigation of clinched joints, Materials Science and Engineer, vol. 39/2. pp. 65-74.

[2] M. S. Joun, H. G. Moon, I. S. Choi, M. C. Lee, B. Y. Jun (2009), Effects of friction laws on metal forming processes, Tribology International 42. pp. 311329

[3] Z. Wang, T. Suzuki (2018), Friction law in dry metal forming of materials with work hardening, Procedia Manufacturing 15. pp. 475-480

[4] Y. Tamai, T. Inazunmi, K. Manabe (2016), FE forming analysis with nonlinear friction coefficient model considering contact pressure, sliding velocity and sliding length, Journal of Materials Processing Technology 227. pp. 161-168.

[5] S. Dou, J. Xia (2019), Analysis of Sheet Metal Forming (Stamping Process): A Study of the Variable Friction Coefficient on 5052 Aluminum Alloy, Metals 9.853

[6] T. Sadowski, T. Balawender, P. Golewski (2015), Technological Aspects of Manufacturing and Numerical Modelling of Clinch-Adhesive Joints, SpringerBriefs in Applied Sciences and Technology, Computational Mechanics

[7] S. Coppieters (2012), Experimental and numerical study of clinched connections, PhD dissertation, KU Leuven

[8] Sz. Jónás, M. Tisza (2018), Finite Element Modelling of Clinched Joints, Adv. Techn. and Mat., vol. 43. No. 1.

[9] Sz. Jónás, M. Tisza, D. Felhős, P. Z. Kovács (2019), Experimental and numerical study of dissimilar sheet metal clinching, AIP Conference Proceedings 2113 